\title{
The problems and perspectives for the introduction of high-rise construction in Russian cities
}

\author{
Anna Pershina ${ }^{1, *}$, Mehman Radzhabov ${ }^{1}$, and Tatyana Dormidontova ${ }^{1}$ \\ ${ }^{1}$ Samara State Technical University, 194, Molodogvardeyskaya St., 443001, Samara, Russia
}

\begin{abstract}
The propose of academic affairs is discovery the principal areas of concern high-rise construction in Russia. Examples of modern Russian and foreign high-rise construction are considered in the work. The most important problems and their solutions for Russia are identified on their basis. The everyone area of concern is considered separately. Ecology problems and influence of high-rise construction for the healthy and psychological effect of people are considered special. High-rise constructions influence negative and positive for urban environment in Moscow and Samara cities. The experience lack, defects in requirements document, which don't include all high-rise constructions specific, system problem of construction and often non-availability of proper control at the existing requirements document result for complexity of designing, construction and operation. At this moment, high-rise constructions temp is increasing in Moscow. Feasibility of high-rise buildings come up in regions of Russia. The reasons include high material inputs, irregularities of requirements network and utility lines and maintenance problems. The researching follow up of conclusions and recommendations for high-rise constructions development in Russia. The reasons of high-rise buildings are urbanization of people and necessary of concentration labor supply. The important tasks for organization are creating compact urban environment, decrease urban area for development, using an innovative technology for construction and properly maintenance. The balance between the preference of high-rise construction, inputs for construction and influence for ecology are resolve for this task.
\end{abstract}

\section{Introduction}

In the modern world, urban process has brought to appearance a lot of big city. An enormous number of people were reasons for appearance of high-rise buildings. Today skyscrapers are inherent part of megapolis. The progress of the construction and research and technology base, the deficit of developed infrastructure and communication systems and the increase of the value of land plots, as well as an increase of the prestige of skyscrapers have been the reason for this. The skyscraper is height more than 75 meters or more than 25 floors at the Russian classification, In the world classification height is more than $100 \mathrm{~m}$ meters.

*Corresponding author: mironova163@mail.ru 
The first high-rise buildings in the world appeared at the end of the XIX century in Chicago. The huge theoretical and practical experience have found, the main problems have been discovered for all ways of high-rise buildings design and construction for the more than one hundred years. There are variety skyscrapers stagger everyone's imagination. The enormous height, plasticity form, flexible planning, construction complexity brings them to the innovation area in the realm of construction. The high-rise buildings have distinct functions such as hotels, offices, apartment houses.

In Russia, the first high-rise buildings were constructed in thirty years of twenty ages. From eight scheduled high-rise buildings, just seven were constructed in Moscow. The project "Counsel palace" is height 430 meters wasn't constructed (picture 1). The details of Stalin-style skyscraper have been Moscow symbols, namely individual architectural style, arrangement and sharp distinction from early constructed buildings. The main building is Moscow Government University in Sparrows mountains. (picture 2). The next years there were general buildings and feasibility of skyscrapers were postponed on indefinite period. This decision brought to intense lag in the realm of construction from lead country of the world.

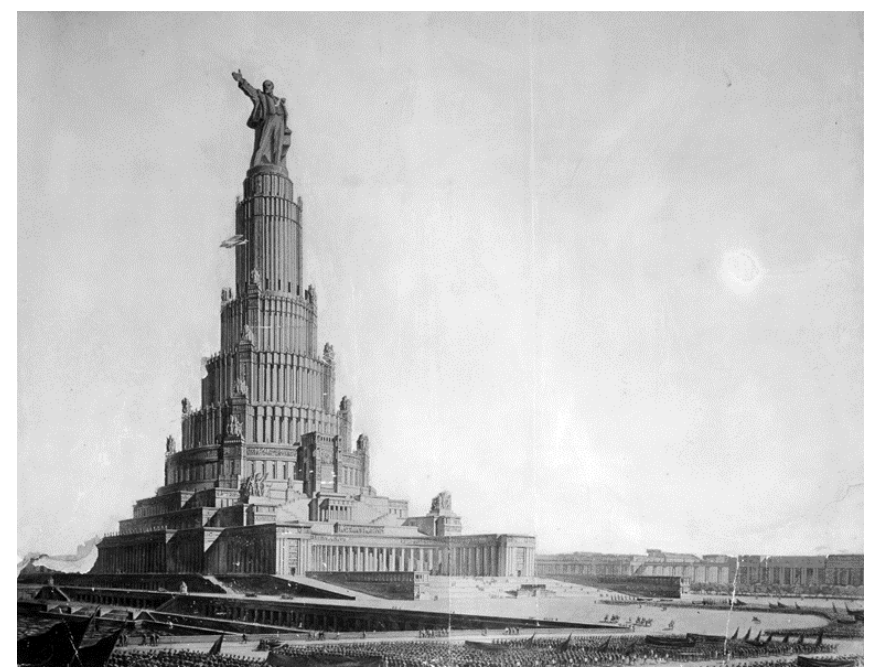

Fig. 1. The project "Counsel palace".

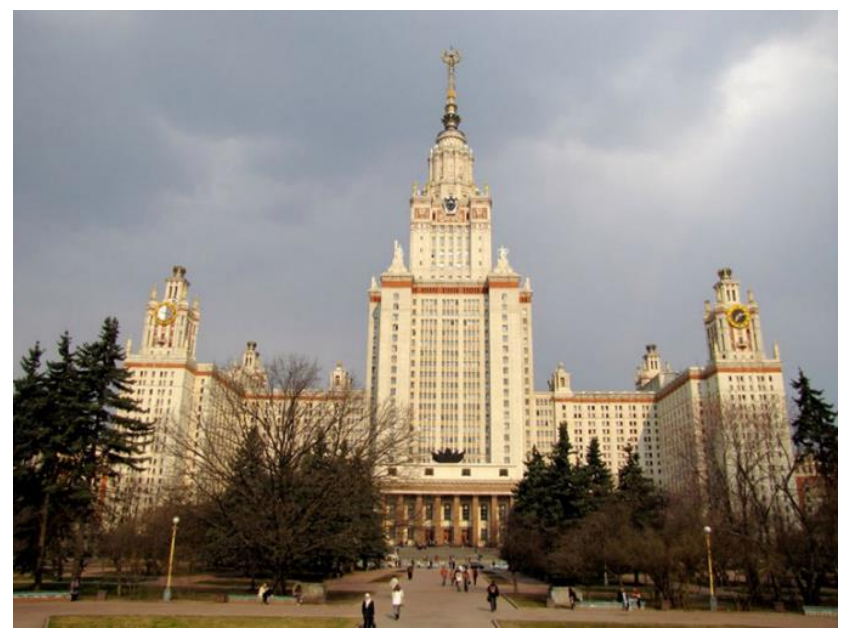

Fig. 2. Moscow Government University. 
The Moscow City is the first skyscraper in the modern Russia. The first planned heights of new modern blocks of buildings were from 240 to 612 meters, but built height are from 85 to 317 meters. The foreign specialists were involved in design and construction. The many problems were caused during the construction process. The deadlines weren't observed. The original project was rejected. The highest building "Russia" wasn't constructed as a result. This ensured that the problems of high-rise buildings were discovered and gotten valuable researching. The experience lack, defects in actual requirements document for high-rise buildings and the system problems of construction followed to the problems on all stages of the project. This ensured that the first requirements document for high-rise buildings were approved and published in Moscow, such as Moscow City Construction Regulations 4.192005 "Temporary requirements document for multifunction high-rise buildings and complexes in Moscow city" and official regulations 267.1325800.2016 "Buildings and highrise complex" was published in 2016 year. The new high-rise buildings and complexes often appear. The skyscrapers are quite appropriate, but have something issues. [4, 5].

The high-rise buildings have slow temps in the others Russian cities. The buildings mainly are 100-150 meters' height in the big cities. The highest appreciable building "Lahta Center" was have started to construct in 2012 year in Sankt-Petersburg. It will be the highest building in Europe. The building will 462 meters and will be able supposed in 2018 year.

\section{Materials and Methods}

The high-rise construction methods were analyzed for them estimate realm. The most problem aspects were discovered, estimated their actual and difficulty of architecture and engineering solution. The big worldwide experience is good for prosses solution problems of high-rise construction. High-rise construction problems shall be resolve by complex methods of attack. The non-typical and unique methods are used. The worldwide experience is transformed to surrounding realty. The Europe experience is more useful and applicable. Each problem aspect and examples will be able examined.

The many materials and technical resources needs to high-rise construction, such as a lot of metals, concreter, expensive engineering equipment, manpower, transports and others. The less than $70 \%$ of inside volume of skyscraper might be used if design has been performed good, other part is used for support elements, stairwells and wells. The $80 \%$ of volume usually is used in the common building. Until 30 engineering systems are used in skyscrapers. The strongest concreter sort was used for construction of tower "Federation" (Moscow-City) for example. The more improved concreter already was used for tower "Eye" and unique concreter line was used for blend delivery at a great height. The use of secondary materials, construction automation, design is done with accordance requirements document, recycled materials resolve these problems [6, 7].

Profitability of the high-rise construction hold a special main place in analyses. The accommodation in skyscrapers are elite realty for many reasons and it limit them expansion. The big company offices more often locate in skyscrapers. One of more problem is location as usual in the center of city. This is main reason for expensive accommodations price. Despite the fact, the experience was and the social accommodations located in the skyscrapers. The burning issue was due to the slums were pulled down, including the famous Kowloon. That problem was resolved by a lot of built skyscrapers. These were very compacted building up. The accommodation standard was 2,2 square meters for one adult. A lot of quantity of accommodation were built in a brief time due to a plot of land were saved a lot. The living space was increased in percent to $10 \mathrm{~m} 2$. An analogous situation was observed in Singapore. Here were built HDB residential complexes, which are social housing. From the Hong Kong variant they were distinguished by more spacious apartments, better landscaping and complex building up $[8,9]$. 
Ensuring the competent development of transport infrastructure shall be commensurate with the built upness and the flexible distribution of automobile traffic. It is known that building high-rise buildings are reason of a significant increase in population density, which requires the presence on the inner yard of enough parking spaces. There is a need for more parking, the expansion of road networks is required due to the increased number of cars. Huge areas of fertile land roll under the asphalt. There is less space for landscaping and site improvements. A big traffic leads to a high concentration of exhausts in the air. Skyscrapers can accommodate an enormous number of people, and their movement requires a welldeveloped network of public transport. The construction of an underground metro or overhead monorail allows to resolve most of the transport problems. But the developed metro network requires a lot of material resources. There are several ways to solve these problems in the worldwide experience. Laws are introduced restricting the use of a private car, as well as their importation in Singapore. A well-developed network of public transport, together with a decrease in the number of cars, helped to avoid a transport collapse. Dubai has another situation; the high-rise buildings were located at a considerable distance from each other. Multi-level road junctions were built at the appeared large spaces. They were designed for the growth of the city in the future.

In many Russian cities, the problem of parking spaces shortage is becoming pressing problem with annual increase of cars on the roads. While dense urban building up does not allow to locate enough of parking on the street especially in the city center. One way of the solution is creating various systems of multistage parking lots that occupy the minimum area. The simplest solution is a multistage covered parking lot, which is in inside of new residential areas. The covered parking lots usually don't enough in case of a dense building up construction. Another wildly solution is underground parking. The most part of constructed high-rise office centers have underground parking. The modern automated parking lots are even more rational from the point of view of minimizing the economy occupied area (Picture 3), because such systems do not need the area under the ramp and reversal platforms, and the erection is much cheaper than capital construction. These parking lots are mobile systems that can be dismantled and moved to another location $[10,11]$.

The design of parking is carried out in accordance with the requirements of 113.13330.2012 "Parking", as well as considering the specifics and style solutions inherent in each object in Russia. Aboveground parking shall be provided with a height of no more than 9 floors, underground parking shall be no more than 5 underground floors.

The most compact and at the same time capacious parking "Car Tower" (Picture 4) is in Wolfsburg city in the German near the factory of the company "Volkswagen". It is made in the form of a giant glass pillar with cells, which one car can accommodate each of. Cars are delivered to a free cell with a special lift. As a result of to this solve, up to 800 cars can fit in a small area.

Recently, the problems of ecology are becoming increasingly important, there is a tendency to develop economic and environmental technologies. The special attention is devoted to energy efficiency and environmental protection. This is reflected in all stages of construction and maintenance of the high-rise building. There are very different approaches to this issue. This can be the introduction of such technologies in existing buildings, as well as completely new projects, originally created under the influence of "green" standards and technologies. 


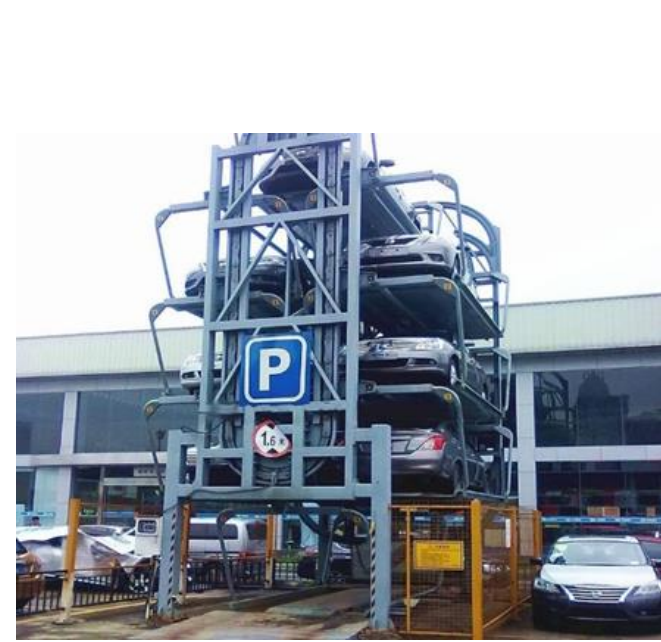

Fig. 3. Automated parking

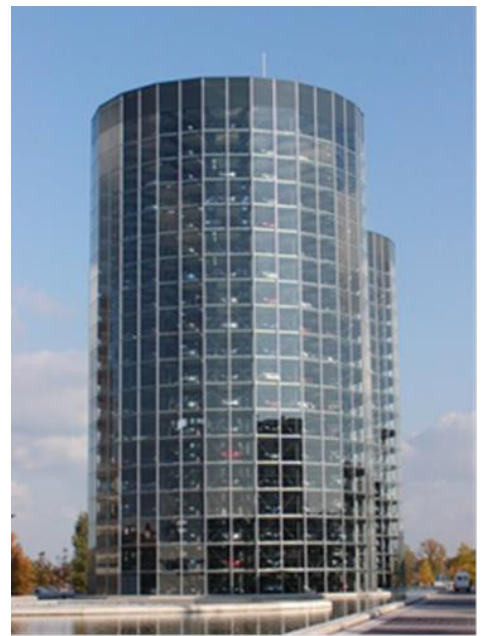

Fig. 4. Parking "Car Tower", German. Wolfsburg city.

Almost all modern high-rise buildings pass environmental certification according to international standards (LEED, BREEAM and others). Concentration of people in a relatively small area leads to the accumulation of a lot of daily trash. A garbage is used technically very difficult in skyscrapers. The most common collection of trash in skyscrapers' apartments occurs floor by floor. Services need for the timely collection of trash and further utilization. Sorting of trash is especially actual for skyscrapers. The question of shading is also very important, there are standards of insolation that shall be met. Large shaded areas appear in conditions of high-rise buildings up. Sunlight may not be enough due to it will negatively affect to the human health and some plant species [12].

Important is the impact on the physiological and psychological health of a person, statistics are known from the results of research by scientists from the University of Canada, Victoria, that people living above the 9th floor are three times more likely to turn to neuropathologists and psychiatrists than those who live in low-rise buildings[13]. Many doctors have opinion that rarefied air and a sharp change in atmospheric pressure at high altitude are not useful for the heart and blood vessels. There are high-speed elevators, which accelerating up to 16 meters per second in most skyscrapers. Some people do not have time to adapt when lifting a sudden change in pressure therefore they have darkening in the eyes and a ringing in the ears. Video ecologists argue that the psychosomatic man is negatively affected by the very faceless appearance of high-rise buildings with a lot of identical windows, monotonous inaccessible walls, depressing the gray veil in the windows (the lower boundary of the rain clouds is just at an altitude of about $100 \mathrm{~m}$ ). An uncomfortable visual environment is created provoking the "big city syndrome", which is often manifested in the aggressiveness of a person. Psychologists have proved that the percentage of suicides is always greater and $80 \%$ of those who commit suicide live above the 9th floor in places of mass building up skyscrapers.

Security issues are importance in high-rise buildings, because organization of evacuation routes requires compliance with the mass of regulatory sources, due to the complexity and length of the paths providing access to the exits. Experts argue that, the use of noncombustible materials is impossible, despite the high development of technologies in construction. Therefore, even in the newest houses a fire is a real threat, for example, the burning of the CCTV tower in Beijing in 2009 and the fire in the tower "Olympus" in "Grozny-City" in Chechnya in 2013. Fire danger for people in high-rise buildings is exacerbated by the fact that unlike low-rise buildings, evacuation is greatly hampered, and 
the complexity of fighting fires increases. The solution is considered by the example of the highest building of the Burj Khalifa. Burj Khalifa has nine special shelter areas (safe areas), which are protected by layers of reinforced concrete and sheet refractory coatings. Their walls can withstand by the fire for 2 hours. Each safe area is equipped with a special ventilation system. Sealed fireproof doors prevent the penetration of smoke. People can hide in safe areas until the emergency services take control of the situation or their turn for evacuation approaches. The fire lift is designed to move 5,500 $\mathrm{kg}$ (50-60 people). The early warning system works continuously for 24 hours a day. As soon as a signal is received to the smoke detector and the temperature sensor, an automatic water extinguisher is triggered and a system of powerful fans. They pour clean cool air into the building through refractory air ducts. Fresh air displaces smoke from the stairwells, ensuring the safety of evacuation routes [14].

For high-rise construction in modern Russia has not yet fully approved the requirements document. It is impossible to build obviously quality facilities that meet modern standards of safety and comfort, while using outdated technologies. For sustainable development highrise construction requires new regulation, simplification of the approval procedure for the joint requirements document, GOST and technical regulations. Today every development project becomes a testing ground for designers and builders in fact. Almost all high-rise under construction buildings are innovative and each of them strives to become better and more difficult than others in Russia.

The main problematic aspects and some examples of their solutions were considered, we will analyze a concrete example of the introduction of a high-rise building in Russia. An erected three-section high-rise building will be considered in the city of Samara at the corner of the crossing of Vilonovskaya and Sadovaya streets (Picture 5). Its height is $140 \mathrm{~m}$ and this is the tallest building in Samara now. It is noteworthy against the background of the Samara building, but among modern high-rise buildings it does not stand out. The surrounding buildings are much smaller by number of floors s, this makes it the dominant one in the area. Many residents of Samara are negative about the appearance of this building. What are the reasons? They are many, both objective and not very much. The building contrasts strongly with the surrounding buildings, creating the impression of randomness. The building is in a cramped environment, the area of the adjacent territory is too small for such a large object. The lack of parking spaces, the total area of which is $3200 \mathrm{~m} 2$ according to the developer, and in fact a two-storey underground parking with a total capacity of 66 cars and a closed courtyard area, which is prohibited from parking, which clearly does not meet the needs of the tenants of the house. Residents use nearby roads to park their cars due to lack of parking spaces, thereby the carrying capacity dramatically reduces of already big traffic. It should be noted that such buildings create some additional problems on the transport network, because there are trade and office premises on the first floors for which parking spaces have not been designed, which additionally creates congestion of the transport network and creates an unfavorable road situation. A lot of residents in this building also needs social facilities in the area (kindergartens, schools, hospitals). The improvement of the territory has only a children's playground above the underground parking (Picture 5) and a place for placing trash containers. The cost of apartments is one of the highest in this house in the city despite the above data. This building is an unfortunate example of high-rise construction, because aerodynamic vortex flows are created due to improper location on the ground constant that create an uncomfortable environment for staying at the playground, lack of landscaping, parking spaces, recreational areas and sports. These problems are typical not only for Samara and for many Russian cities, where high-rise buildings are erected [15-20]. 


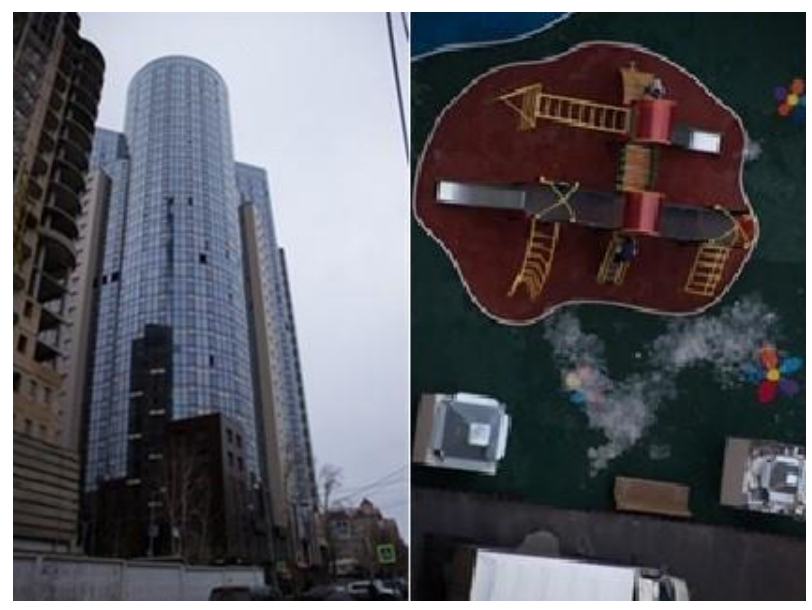

Fig. 5. The facade of a three-section building at the crossing of Vilonovskaya and Sadovaya streets in the city of Samara. Children's playground in the courtyard of a three-section building at the crossing of Vilonovskaya and Sadovaya streets in Samara.

\section{Results}

The Russian construction industry has a lack of experience in high-rise construction and generally has more problems in their construction than in developed countries in this area. The problems appear because of the climate, the proper location in the existing urban development, the lack of materials, technologies and construction equipment suitable for building high-rise buildings. As well as there are lack of right requirements documentation and proper compliance control, the existing requirements for territorial planning and zoning in the city, construction and maintenance of the building.

There are various approaches to solving the problems discussed in world practice. Any approaches however aren't applied for Russian reality. The infrastructure of a high-rise building solution is more urgent for Russia. Among them are modernization of engineering systems, transport accessibility, improvement of the adjacent territory, application of modern systems for building maintenance. We conclude that the correct location of a high-rise building in the urban area is important on the example of a building in Samara.

\section{Conclusion}

The importance of this topic is that any building in the city directly or indirectly affects its inhabitants. The growth of the largest Russian cities leads to a shortage of territory, an increase in the population, the need for its placement. There are all prerequisites for the development of high-rise construction. An analysis of this area problems allows to find optimal solutions for a certain territory, design features for each building separately.

It is impossible to make a conclusive conclusion about the necessity or inadmissibility of high-rise construction in the Russian realities. The introduction of high-rise complexes into the largest Russian cities seems justified. High-rise buildings allow to avoid the widening of the city territory, creating a "compact" urban environment in the conditions of a lack of territories. The concentration of the working population in the business center is also justified for economic reasons. A compromise is needed between the advantages of high-rise construction and the costs of building them. The construction of high-rise buildings leads to even greater problems and only strengthens the negative attitude of the population towards 
high-rise construction in an incorrect place for their construction for example, among lowrise buildings surrounded by narrow streets. The issue of optimizing the relationship between the density of building up, the width of road gaps, quantity of parking spaces and make these adjustments to the requirements documents ensuring proper control over the compliance of high-rise buildings with all regulatory requirements, especially at the stage of erection and putting into the operation of buildings it is necessary to regulate now in Samara, however, as in other Russian cities with a million population.

\section{References}

1. V. P. Generalov, The special aspects of designing high-rise buildings: a study guide, 296 (2009)

2. V. P. Generalov, E. M. Generalova, The development perspective of high-rise buildings topology, The cities future, 1(18), 13-18 (2015)

3. V. P. Generalov, E. M. Generalova, The skyscrapers era megatall, 334-335 (2013)

4. V. P. Generalov, E. M. Generalova, Prerequisites for the formation of high-rise social housing complexes in Hong Kong, 379-380 (2014)

5. E. M. Generalova, K. E. Galstyan, Analysis of the existing regulatory structure for the construction of high-rise buildings in Russia, 52-55 (2015)

6. A. S. Mironova, Aspects of utilization of nanotechnological wastes in the construction industry, 1(120), 58-59 (2009)

7. A. S. Pershina. Aspects of the Formation of Modern Architectural and Expressive Facade Designs of Civil Buildings Taking into Account Application of Nano-Materials, 132135 (2016)

8. E. M. Generalova, V. P. Generalov, Specificity of modern architectural and spatial environment formation of cities (illustrated by South Korea), 11, 46-51 (2015)

9. V. P. Generalov, E. M. Generalova, Energy efficiency and environmental friendliness of mass affordable housing in the case of Hong Kong, Sustainable architecture. 4(21), 3238 (2015)

10. V. R. Vuchic, Transport in cities that are convenient for living, 413 (2011)

11. S. F. Zhilkin, E. A. Akhmedova, T. B. Karakova, Urban Strategic planning (2001)

12. T. Y. Vavilova, The principle of environmental compliance as a condition for the high technology industries development, 1 (2), 110-116 (2010)

13. D. Cappon Mental Health in the High-Rise CJPH, 62(5), 426-431 (1971)

14. V. P. Generalov, E. M. Generalova, Identifying the distinctive features of the concepts of "comfort of living" and "comfortable living environment", 2(23), 85-90 (2016)

15. T. V. Filanova, V. M. Melnikova, Functions Evolution and structures in the largest city (For example by Samara), 4, 118-123 (2010)

16. N. A. Lekareva, Planting standards and planting construction development, 6-9 (2011)

17. Henley Simon. The Architecture of Parking, (New York, Thames and Hudson, 2007)

18. A. A. Kayasov, Perspectives for the business centers development in Russian regions, 16-20 (2011)

19. V. Ya. Lyubovny, Cities of Russia. Problems, possible ways of development and improvement of management, 14-16 (2012)

20. E. A. Akhmedova, Planning aspects of the perspective agglomerations transformation. 40-45 (2009) 